\title{
PROGRAMMATIC, SYSTEMATIC, AUTOMATIC: AN ONLINE COURSE ACCESSIBILITY SUPPORT MODEL
}

\author{
Kathleen Bastedo \\ Center for Distributed Learning, University of Central Florida \\ Amy Sugar \\ Rolling College \\ Nancy Swenson \\ Center for Distributed Learning, University of Central Florida \\ Jessica Vargas \\ Rollins College
}

\begin{abstract}
Over the past few years, there has been a noticeable increase in the number of requests for online course material accommodations at the University of Central Florida (UCF). In response to these requests, UCF's Center for Distributed Learning (CDL) formed new teams, reevaluated its processes, and initiated a partnership with UCF's Student Disability Services (SDS) office to address these needs. This article presents the Online Course Accessibility Support Model that was developed and implemented by CDL. This model was designed to provide a scalable and programmatic approach to creating accessible online course materials. It identifies the following three strategies to address these needs: (1) teach faculty Universal Design for Learning (UDL) principles through professional development programs regarding the ways in which UDL relates to accessible online materials for new courses; (2) provide legacy faculty members with the opportunity to update their existing online course materials to accommodate diverse learners; and (3) expedite accommodations for online course materials to address immediate needs (e.g., situations in which a student registered with SDS is currently enrolled in an online course that contains some inaccessible materials). As a result of implementing this model, communication between CDL and SDS improved, roles related to making course materials accessible were defined, and students gained access to accessible online course materials more quickly.
\end{abstract}

\section{KEYWORDS}

Accessibility, online course materials, systematic approach, online course accessibility support model

\section{INTRODUCTION}

In fall 2002, approximately 1.6 million students across the United States took at least one online course, and by 2010, that number had grown to over six million [1]. By 2011, it was reported that $31 \%$ of all higher education students took at least one online course in the fall term [1]. Because of this unprecedented growth, educators and administrators began to note the diversity of students taking these courses. Students with disabilities represented approximately $11 \%$ of all postsecondary students in 2008 [2]. That was also the year that the ADA added an amendment to "broaden the scope of protection provided to individuals with disabilities" [3]. The 2008 amendment afforded more opportunities for students with disabilities to apply to institutions of higher education.

In addition to the increase of students with disabilities entering higher education, many of them are taking advantage of the benefits online courses provide, some of which include convenience and flexibility (e.g., students no longer need to manage traveling to and around campus; they may use a home computer fitted 
with the assistive technology that meets their needs; some students may no longer require the assistance of a note taker; students have the ability to choose from a variety of online tools to submit assignments and to interact with peers and the instructor) [4].

Along with the growth of online courses, the increase in diversity, and the growth of the student body, new technology also began to emerge. According to the Department of Justice, Civil Rights Division, "technological innovations have opened a virtual world of commerce, information, and education to many individuals with disabilities for whom access to the physical world remains challenging" [5]. The institution must understand these challenges in order to determine how to provide faculty with the resources and information they need to create accessible online course materials. This understanding helps to ensure compliance with laws related to accessibility, such as the Rehabilitation Act of 1973 and the Americans with Disabilities Act (ADA), as they apply to these situations.

Based on the laws mentioned above, most institutions already have a designated department that assists faculty in providing accommodations for students in face-to-face classrooms. However, other than these laws, there is no standardized approach for how institutions of higher education should accommodate students with disabilities in online courses. In the 2010 Managing Online Education Survey of 183 colleges and universities, it was determined that many campuses do not have formal policies and procedures to ensure that their online courses and programs are compliant with ADA mandates [6]. Thirty-four percent of respondents said that the responsibility for complying with ADA falls on the individual faculty member teaching the online course, while $24 \%$ reported that the responsibility falls on academic programs or departments. Furthermore, only $9 \%$ reported that their college has a central office that reviews a sample of online courses to ensure ADA compliance, whereas $17 \%$ reported that they do not have any institutional policies in place related to ADA compliance. It is also vital to mention that according to the U.S. Department of Justice "use of an 'ad hoc' or 'as needed' approach to IT accessibility will result in barriers for persons with disabilities" [7].

As mentioned above, each institution manages these matters differently. Some institutions have a designated department to address the accessibility of online courses, such as the Assistive Technology Initiative at George Mason University in Virginia [8] and the University of Illinois at UrbanaChampaign's Illinois Center for Information Technology and Web Accessibility [9]. Some institutions, such as UCF, do not have this specific type of department and rely on the support of individuals from different departments to address this need. As a result, UCF created a systematic model to address the accessibility of online course materials.

\section{ONLINE COURSES AT UCF}

UCF offered its first online course in 1996 when the student body numbered only 26,324 [10]. Since then, there has been a steady increase in the volume of online courses produced by UCF. In the Fall 2011 semester, over 27,000 of the total of 58,698 UCF students took at least one web or video-based course. Approximately $11 \%$ of UCF students enrolled exclusively in online courses. Additionally, 33\% of UCF's student credit hours are currently generated from online courses [11]. With such extraordinary growth in student attendance and online course availability, the number of students with disabilities enrolling in courses increased slowly but steadily. According to statistics provided by SDS, the number of registered students with disabilities at UCF grew from 161 in 2003 to more than double that in the following year, and in Fall 2012 that number increased to just over a thousand students (see Figure 1). 


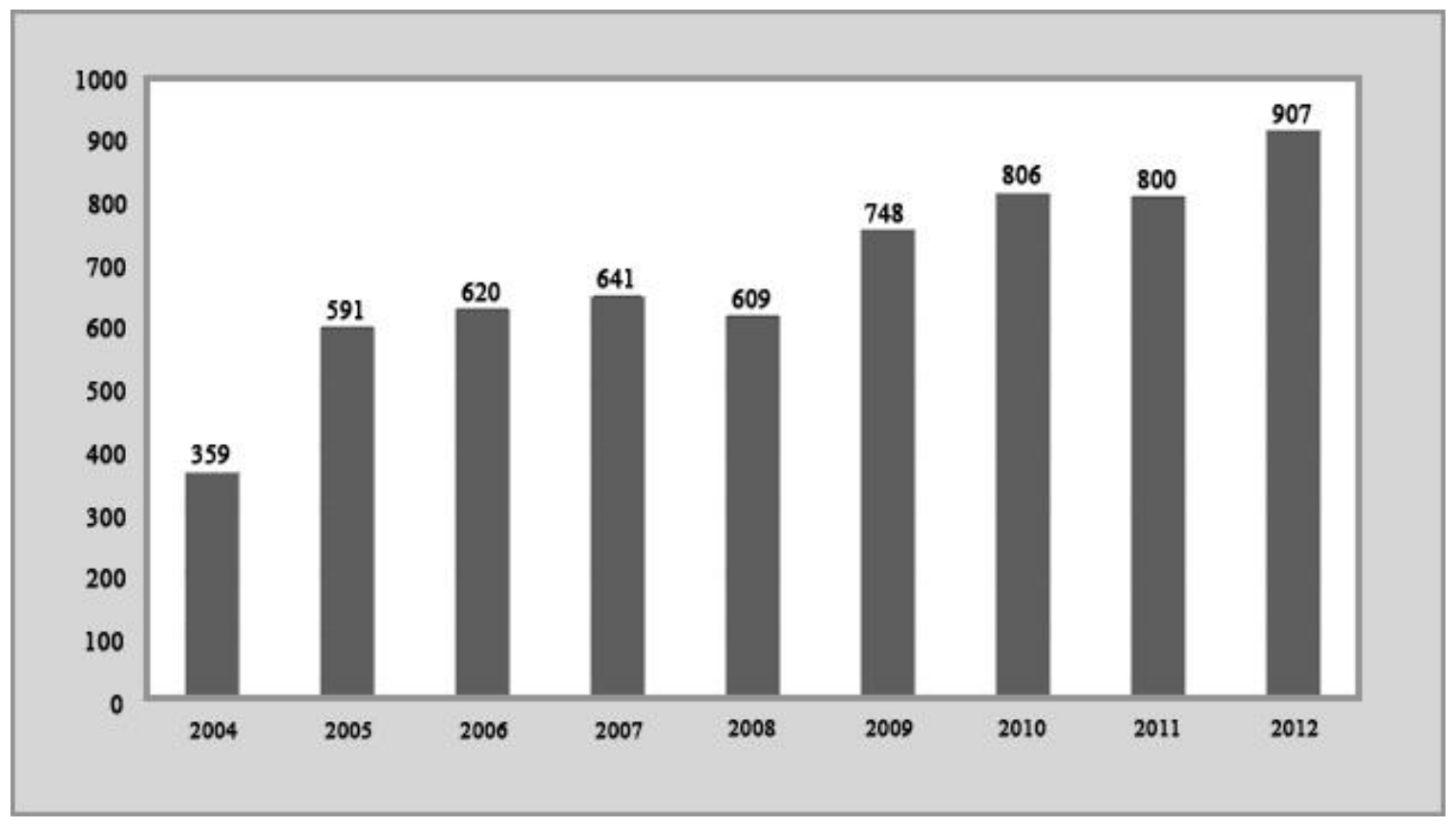

Figure 1: Number of Students Registered with SDS at UCF by Year

At UCF, CDL serves as the central agent for online learning and has been at the forefront of creating accessible online course materials since 1996. Historically, SDS has provided academic accommodations for face-to-face classes to qualified students with disabilities. However, when students with disabilities registered to take an online course, these accommodation requests were handled on a case-by-case basis without a programmatic approach in place. In addition, the number of students registered with SDS who were enrolled in online courses grew from 26 in Spring 2012 to 90 by the following semester. Meanwhile, rich media elements (e.g., various audio and video web links, audio lectures, graphics, screencasts) were being added to these courses at a steady rate. Since there was no programmatic approach to indicate who was responsible for making content and media accessible, content was often removed from the course.

Due to this gap in services, the steady increase in the number of students with disabilities registering for online courses, and the increasing need for accessible online course materials, UCF's senior-level administrators stepped in to determine whose responsibility it was to provide online course material accommodations. Once accountability was established, CDL created a workflow process to address these accommodation requests. CDL and SDS worked to create a task force, the Campus-Wide Accessibility Initiative, comprised of representatives from various departments whose job is to periodically review and improve current workflow processes (e.g., investigate new software designed to simplify accommodation needs). Although means for actualizing processes across departments were realized, CDL also met internally to form the Big Picture Accessibility Group. This group's goal was twofold: first, to articulate how teams within CDL would manage accommodation requests from SDS, and second, how to inform, instruct, and assist faculty members about how to be proactive in retrofitting current course content and creating accessible content from the outset. This CDL group became solely responsible for conceiving and deploying the following systematic model to address all accessibility concerns for distance learning at UCF with the hope of getting closer to the goal of automating this process.

\section{ONLINE COURSE ACCESSIBILITY SUPPORT MODEL}

Several meetings occurred in order to systematically establish workflow processes between CDL and SDS. The Online Course Accessibility Support Model (see Figure 2), developed by CDL, helped to streamline the creation of accessible online course materials. 


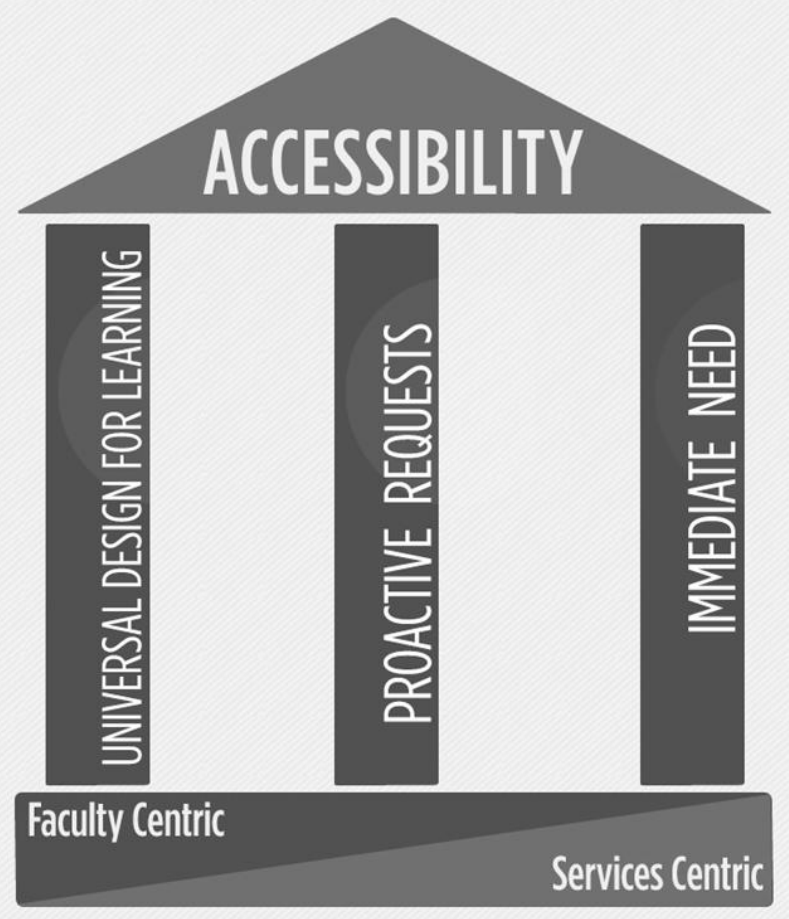

Figure 2: Online Course Accessibility Support Model

This model consists of three pillars that support and promote the overarching theme of accessibility in the online environment. Each pillar represents a process specifically designed to address the three types of accessibility requests. The base of the model represents a continuum of where the primary responsibility falls: from faculty centric, in which the faculty has primary responsibility, to services centric, in which accommodations are mostly provided by SDS. The services provided by CDL can occur at any point across the continuum; however, most of the services provided by CDL occur in the middle of the model.

\section{A. Universal Design for Learning}

The first pillar, UDL, represents the application of UDL principles to the design and development of new online courses. When faculty apply these principles to online course materials, it not only benefits students with disabilities, but it also benefits students of varying abilities (e.g., reading level, age, English as a second language). UDL principles and strategies are integrated into professional development programs offered by CDL, during consultations with instructional designers, and through various campuswide communications and support venues. This pillar is on the faculty-centric side of the continuum for faculty members who choose to design and develop their course with UDL principles and accessibility in mind. CDL provides support and assistance as appropriate to faculty implementing this approach.

\section{B. Proactive Requests}

The second pillar, Proactive Requests, represents situations in which either the faculty member seeks assistance in making their current online course materials accessible or an instructional designer working with a faculty member offers assistance in making the online course materials accessible. CDL has provided course design and development support to faculty as far back as 1996, and since that time, over 1,000 faculty have completed CDL's flagship professional development program, IDL6543 [11]. For faculty members who completed this program years ago, it's likely that they have added new content and 
Programmatic, Systematic, Automatic: An Online Course Accessibility Support Model

new technology tools to their online courses. The proactive requests represent a process to help these faculty members review and improve the accessibility of their course materials even when there is not an immediate need for accommodations. This pillar is in the middle of the faculty-centric and servicescentric continuum since the responsibility is shared by CDL and faculty.

\section{Immediate Need}

The third pillar, Immediate Need, represents situations in which a student with disabilities is enrolled in an online course and accommodations are required for the current semester. CDL created a workflow to identify the tasks and responsibilities of CDL, SDS, and faculty in making online course materials accessible. This workflow helped CDL and SDS develop more formalized timelines when courses fell into the immediate needs category. This need is located on the services-centric side of the continuum since SDS and CDL provide the necessary support and are responsible for making the required accommodations when there is an immediate need.

Implementing the Online Course Accessibility Support Model improved communication between CDL, SDS, and the various departments on campus who provide faculty support services. Meetings are scheduled each semester with representatives from these departments to determine whether there are ways to improve these processes, increase the efficiency of meeting the needs of students, and prevent duplication of efforts between departments. The workflow processes and communication between CDL teams also improved and became more efficient. Another benefit of creating this model has been an increased awareness across campus of the need to make online course materials accessible. All three approaches work together to address the potential need for accessibility accommodations.

\section{UNIVERSAL DESIGN FOR TEACHING AND LEARNING ONLINE}

\section{A. Universal Design for Learning}

The goal of the first pillar in the Online Course Accessibility Support Model, UDL, is to educate and enable faculty members to create accessible and universally designed online course materials as they develop new courses. The Center for Applied Special Technology (CAST) defines UDL as "a set of principles for curriculum development that give all individuals equal opportunities to learn" [12].

The following benefits naturally occur when UDL principles are applied:

- Updated courses using UDL will address the needs of diverse learners.

- As accommodation requests are received, there is less work that needs to be done to ensure that students have access to online course materials. Retrofitting an online course to meet an immediate accessibility need may require more time, more resources, and more expense compared to creating accessible course materials from the start [13].

- UDL benefits all students regardless of capability. For example, video captioning enables those with visual impairments to access the content, but it also helps visual learners remember information. Additionally, captions help to reduce language barriers and to improve comprehension for viewers who speak English as a second language [14].

\section{B. Professional Development Programs}

The Center for Distributed Learning promotes accessibility and UDL through several venues, including two professional development programs designed for faculty who are designated to teach online. The first professional development program, IDL6543, is a 10-week mixed-mode course that is required for faculty who will design, develop, and teach their own mixed-mode or fully online courses at UCF. IDL6543 provides faculty with the pedagogical and technological foundation needed to design and develop effective online courses. The course consists of three face-to-face meetings, weekly online readings, activities, assessments, and several one-on-one consultations with an assigned instructional designer. The minimum requirement of this course is to develop a syllabus, schedule, course/instructor introduction, and one module of content. 
During the second week of IDL6543, faculty members complete a learning module on accessibility and UDL. This module provides faculty with an overview of accessibility related laws and issues, and provides strategies for designing and developing accessible and universally designed materials, including the following:

- Use the most accessible materials when possible (e.g., HTML).

- Format course materials to be accessible (e.g., apply heading styles).

- Add a brief and meaningful text description or alternative text (alt text) for all images.

- Search for materials that are in an accessible format (e.g., videos with captions).

- Consider accessibility and UDL when selecting multimedia elements for inclusion in online courses.

- Include a syllabus statement related to accessibility and resources available to students with disabilities.

The above concepts are also integrated throughout this professional development program and are readdressed during the weekly assignments and assessments, during a face-to-face presentation by CDL's programming team, and during multiple consultations with the assigned instructional designer. During each week of the course, faculty members complete Build Your Course Activities in which they apply the theory and concepts presented in the module in order to build a component of their course. These activities teach faculty how to build accessible content within the learning management system, as well as how to make other course materials (e.g., Word, videos) accessible.

The new online course materials developed by faculty are evaluated several times throughout this course using specific IDL6543 course and module rubrics. These rubrics address objectives, interaction, assessment, accessibility, and copyright. Faculty members use these rubrics to self-evaluate their online course materials and to provide feedback to their peers about their course materials during a peer review session. Finally, the online course materials are evaluated by the instructional designer using these rubrics.

The second professional development program, ADL5000, is a self-paced, online course that is required for faculty who are scheduled to teach an existing mixed-mode or fully online course previously developed by another UCF faculty member who has already completed IDL6543. ADL5000 includes several learning objects that cover a variety of topics, including objectives, interactions, assessments, accessibility, and UDL. The accessibility and UDL learning object provide an overview of various types of disabilities (e.g., visual disabilities, auditory disabilities, motor control, and cognitive disabilities), presents potential access challenges in the online environment, and identifies strategies to address these challenges.

In order to provide additional professional development to a wider range of faculty members, CDL began offering Faculty Seminars in Online Learning [15] in January of 2011. These seminars are short 30minute sessions that cover topics related to teaching online. They are co-presented by CDL staff and a UCF faculty member in a face-to-face environment while being streamed live to remote attendees. The seminars are later archived on UCF's Teaching Online website for future viewing. In April 2012 this seminar series focused on accessibility and UDL. This particular seminar provided strategies and resources to help faculty design and develop their online courses with accessibility and UDL in mind.

\section{Campus-Wide Communications and Support}

\section{Provost Letter to Faculty}

In August 2011, UCF's provost, Dr. Tony Waldrop, sent a letter to all UCF faculty related to accessibility of online course materials [16]. This letter is also e-mailed to faculty on a yearly basis and states that while UCF is committed to providing equitable access to all students, it is the responsibility of faculty to ensure the accessibility of their web-based content. Additionally, this letter identifies the services provided by various departments on campus to help faculty create accessible materials. For example, SDS 
Programmatic, Systematic, Automatic: An Online Course Accessibility Support Model

can provide services such as braille materials, electronic files for textbooks, creating a transcript of a recorded lecture, and converting text-based materials into an accessible format. CDL assists faculty members in the design and development of accessible online course materials, including captioning videos from transcripts. The Faculty Center for Teaching and Learning helps faculty members create and design course materials and teaching strategies that will accommodate a wide range of differences among students. A copy of this letter is available for review so that all faculty members have access to the information throughout the year.

\section{Online Resources}

Another important component of UDL is to provide campus-wide resources to empower faculty to create accessible and universally designed course materials. There are several accessibility related resources for UCF faculty on CDL's Teaching Online website. With the increase in the use of multimedia and the changes in features available in the learning management system currently used by UCF, CDL created an Accessibility Tips page for faculty [17]. This page addresses creating accessible content for online courses, using different file formats online, and using multimedia online.

\section{ADDRESSING LEGACY ONLINE COURSES AT UCF}

The Universal Design for Learning process seeks to address how new or incoming faculty to UCF's online program should design new content. There was also a need to address those faculty members who were already teaching online. This prompted the creation of the Big Picture Accessibility Group to create the second pillar of the Online Course Accessibility Support Model, Proactive Requests. These faculty members successfully completed IDL6543 many years ago and have been developing their courses largely on their own but had not yet received an online course accommodation request from the SDS office. With the distribution of the provost's letter, these faculty members became aware of the importance of online course accessibility and learned that some new types of media added to their courses may not be accessible. In light of these developments, it was imperative to have accessibility discussions with these legacy faculty members.

The Proactive Request is a faculty- and services-centric process developed by CDL. The request provides faculty with the opportunity to have their online course reviewed for accessibility issues by CDL's programming team. CDL also works with these faculty members to help make their course content accessible. This approach is considered proactive because the accessibility of the content is addressed before a student registered with disabilities services is signed up to take it. This process also begins the dialogue between faculty and the assigned instructional designer about how best to ensure accessibility in the future by using instructional strategies and best practices.

With the recommendation of the instructional design team, CDL hired a usability checker who is also a part-time student adept at using a screen reader such as JAWS to work on the programming team. The usability checker provides real-world experience when testing course materials for accessibility. There is nothing more effective or efficient than to have the assistance of an end user who has experience using specialized software (e.g., a screen reader) to access and examine online course components.

The results compiled by the usability checker are then summarized and sent to the instructional designer, who discusses the results with the faculty member. The results from this meeting may require the instructional designer to submit additional requests to fix content pages, or the faculty member may need to provide additional material, such as video transcripts.

\section{ACCOMMODATING IMMEDIATE NEED REQUESTS}

While the Proactive and UDL requests are fairly recent developments in the overall accessibility processes at UCF, the Immediate Need request has been in existence since online courses became available for students. As the final pillar in the Online Course Accessibility Support Model, the Immediate Need scenario involves requests from SDS for students who are currently enrolled in an online course who may need immediate accommodations. With an average of two accommodation requests 
related to online course materials per semester prior to the 2012 calendar year, accommodations were handled on a case-by-case basis. During the 2012 calendar year, the online course material accommodation requests increased to an average of 33 requests per semester. At this point it became clear that responsibilities had to be assigned and that a systematic approach to handle these requests had to be devised. Therefore, procedures were formalized to create an efficient workflow process between SDS, CDL, and faculty members.

In conjunction with SDS, the Big Picture Accessibility Group created the Accessibility Support Matrix for Students with Disabilities. This document was designed to help define the roles for SDS, CDL, and faculty members and to create a clear and concise process with the goal of ensuring accessibility of technologies used in an online course. This matrix specifically lists the types of media that are often included as part of online course materials, such as HTML pages, Word documents, PDF documents, PowerPoint files, audio and video files, and other media elements. Each department's role is defined along with an estimated time to resolve a particular accessibility issue. For example, if a faculty member utilizes a video with no transcription or captioning in an online course, SDS is responsible for creating that transcript. If copyright permission is available, CDL's video production team applies captioning using the transcript provided by SDS.

Another process associated with the Immediate Need requests is the Checklist of Accommodations of Online Course Materials (see Appendix A). Four weeks prior to the beginning of a new semester, SDS emails faculty members to inform them when a qualified student with a disability has enrolled in their online course for the upcoming semester. The e-mail includes a link to a particular checklist (Form B or D) depending on the type of accommodation needed. Faculty members complete and submit the online checklist to SDS and CDL. If accommodations are needed, SDS and CDL work with faculty members to assist them in making these accommodations.

The Accessibility Accommodation Workflow (see Appendix B) outlines the process once the checklist is returned to SDS and CDL. After a faculty member identifies a course component that needs to be evaluated for accessibility, CDL forwards any pertinent requests to its individual teams to investigate the media and determine whether a modification needs to be made. Necessary modifications are implemented, recommendations are determined by the designated team, and a summary of this information is provided to the faculty member. It is the faculty member's responsibility to review all changes and submit follow-up requests if necessary.

Together, these documents accomplish what is necessary to ensure an efficient Immediate Need process. The process emphasizes turnaround times so that the student can begin the course on time with accommodations in place. It also clarifies accountability so teams can work together without duplicating efforts. Furthermore, the Immediate Need processes are meticulous in design so that affected courses can be made fully accessible. Because of these processes, no student, regardless of ability, is excluded from the rich media provided in these courses.

\section{CONCLUSION}

The motivation for formalizing and streamlining the university's procedures for accommodating student disabilities in online courses includes the following factors: the rapid growth of UCF's online courses over the past 16 years, a variety of new instructional technologies, and an increase of students requiring accessible content. The Online Course Accessibility Support Model was developed to provide a systematic way to respond to the accessibility requests for online courses at UCF. This model improves services in a variety of ways. For Immediate Needs requests, the model helps reduce errors and duplication of efforts and assigns responsibility for completion of these items. Creation of the model and the yearly release of the provost's letter also raise awareness of UDL principles while helping faculty learn how to address accessibility in legacy courses before there is an immediate need request. Accessibility is now an integral part of the discussion about creating engaging course content. 
Programmatic, Systematic, Automatic: An Online Course Accessibility Support Model

Although significant progress has been made since the implementation of the Online Course Accessibility Support Model, there is still much more work to be done in terms of ensuring access for all. The Big Picture Accessibility Group continues to search for ways to ensure accessibility for all online course materials. For instance, science, technology, engineering and math (STEM) courses are slowly making their way online at UCF. These courses often rely heavily on math formulas. In the past, this required special programming knowledge (e.g., LaTeX) so that students with screen readers could hear the formulas. Yet with newer learning management systems (e.g., Instructure Canvas), creation of math formulas is becoming easier to integrate into online course content. Although the technology is not perfect, it looks promising.

Perhaps the greatest challenge is ensuring that all faculty and technology specialists know how to design online course content with accessibility in mind as online courses are created. Progress in this arena continues as more faculty members learn about these processes. Ongoing support from the UCF administration has been a critical factor in the creation of the Online Course Accessibility Support Model.

This model can serve as a template for creating similar processes for any institution. While this model may not fit each situation or specifically address all issues, it can be used to begin a dialogue about how to best approach a complex and important topic. As institutions continue to grapple with accessibility, the ultimate vision is to produce a course where all students can learn regardless of ability. Although the goal of reaching $100 \%$ accessibility of online course materials may be elusive, it is our intent that online courses be as accessible as possible before a student ever enters into the online environment.

As T. E. Perez and R. Ali wrote in their joint "Dear Colleague" letter to college and university presidents, "because technology is evolving, it has the capability to enhance the academic experience for everyone, especially students with disabilities. Innovation and equal access can go hand in hand" [5].

\section{ABOUT THE AUTHORS}

Kathleen Bastedo, M.Ed., is an instructional designer for the Center for Distributed Learning (CDL) at the University of Central Florida (UCF). She assists faculty with the design, development, and delivery of online courses. She also has had experience creating and teaching an online course about assistive technology for the College of Education at UCF. She earned a master's degree in Curriculum and Instruction from the University of South Florida in 1997. Kathleen has presented at a variety of conferences, including Sloan, ATIA (Assistive Technology Industry Association), and ELI (EDUCAUSE Learning Initiative), regarding accessibility and universal design of online course materials.

Amy Sugar, M.A., is an instructional technologist at Rollins College in Winter Park, Florida. She works with faculty members to integrate appropriate technologies to enhance curriculum design. She previously worked for the Center for Distributed Learning at the University of Central Florida (UCF) as a full-time instructional designer for five years. Amy earned a bachelor's degree in Music Education from Florida State University and minored in Spanish. She taught elementary music for over eleven years in Orange County (FL) Public Schools. In addition, she earned National Board Certification and designed, delivered professional development training to, and participated on curriculum writing teams. In 2007 she earned a master's degree in Educational Technology from UCF. Her online teaching and learning research interests include faculty development, mobile learning, accessibility, and universal design.

Nancy Swenson, M.A., is an instructional designer at the University of Central Florida's (UCF) Center for Distributed Learning. She assists faculty with the design, development, and delivery of online courses. Nancy has a master of arts degree in Educational Technology and a bachelor's in Business Education. Prior to becoming an Instructional Designer, she taught Business Education classes for thirteen years in the Florida public school system. She has also worked as an adjunct instructor at Valencia Community College and Florida Virtual School and is also an adjunct instructor at UCF. Her online teaching and learning research interests include adult learning theory and accessibility of online education. 
Jessica Vargas, M.A., is an instructional technologist at Rollins College in Winter Park, Florida, where she works with faculty members to integrate appropriate technologies to enhance curriculum design. She previously worked for the Center for Distributed Learning at the University of Central Florida (UCF) as a full-time instructional designer for three years. Jessica has also presented since 2004 at a variety of conferences for EDUCAUSE, ELI (formerly NLI), and AASCU regarding the millennial generation's learning styles as well as for Sloan regarding accessibility, universal design, and copyright. She earned a master's degree in Instructional Technology from UCF in 2009.

\section{REFERENCES}

1. Allen, E. I., and Seaman, J. Going the Distance: Online Education in the United States, 2011. Ninth Annual Sloan Survey of Online Learning. The Sloan Consortium, 2011. http://sloanconsortium.org/publications/survey/going_distance_2011

2. United States Government Accountability Office. Higher Education and Disability: Education Needs a Coordinated Approach to Improve Its Assistance to Schools in Supporting Students. Washington, D.C.: United States Government Accountability Office, 2009. http://www.gao.gov/new.items/d1033.pdf

3. U.S. Equal Employment Opportunity Commission. Questions and Answers on the Final Rule Implementing the ADA Amendments Act of 2008. http://www.eeoc.gov/laws/regulations/ada qa final rule.cfm

4. OnlineUniversities.com. The Benefits of Online Ed for Disabled Students. Accessed November 30, 2012. http://www.onlineuniversities.com/articles/students/the-benefits-of-online-ed-for-disabledstudents/

5. Perez, T. E., and Ali, R. Joint "Dear Colleague" Letter: Electronic Book Readers. U.S. Department of Justice, Civil Rights Division and U.S. Department of Education, Office for Civil rights. http://www2.ed.gov/about/offices/list/ocr/letters/colleague-20100629.html

6. The Campus Computing Project and WICHE Cooperative for Educational Telecommunications. 2010 Managing Online Education Survey. http://www.campuscomputing.net/item/2010-managing-online-education-survey-wvideo

7. United States Department of Justice. A Guide to Disability Rights Laws. Americans with Disabilities Act. http://www.ada.gov/cguide.htm\#anchor62335

8. George Mason University. Equity and Diversity Services. http://accessibility.gmu.edu/ati/

9. University of Illinois at Urbana-Champaign. Illinois Center for Information Technology and Web Accessibility. http://www.cita.uiuc.edu/

10. University of Central Florida Office of Institutional Research. University Enrollment and Application Statistics. http://www.iroffice.ucf.edu/enrollment/index.html

11. University of Central Florida Center for Distributed Learning. http://cdl.ucf.edu/

12. Center for Applied Special Technology. What is Universal Design for Learning? http://www.cast.org/udl/

13. Wentz, B., Jaeger, P, and Lazar, J. Retrofitting Accessibility: The Legal Inequality of After-theFact Online Access for Persons with Disabilities in the United States. Braille Monitor. https://nfb.org/images/nfb/publications/bm/bm12/bm1205/bm120504.htm

14. Danan M. Captioning and Subtitling: Undervalued Language Learning Strategies. Meta 49: 66-77 (2004). http://www.erudit.org/revue/Meta/2004/v49/n1/009021ar.html

15. University of Central Florida Teaching Online. Faculty Seminars in Online Learning. http://teach.ucf.edu/professional-development/faculty-seminars/

16. Waldrop, T. G. Provost Letter. Subject: Reminder of faculty responsibility for ADA-compliant course materials and available support services. Email sent to UCF faculty on August 7, 2011.

17. University of Central Florida Teaching Online. Accessibility Tips. http://teach.ucf.edu/resources/accessibility-tips/ 


\section{ACKNOWLEDGEMENTS}

We would like to thank our co-workers, Dr. Patsy Moskal, Dr. Beth Nettles, Marlenys RojasReid, Dr. Kelvin Thompson, and UCF's office of Student Disability Services, for their guidance, help, and constant support.

\section{APPENDIX A: \\ Checklist for Accessibility Accommodation of Online Course Materials Forms B and D}

\section{Checklist for Accessibility Accommodation of Online Course Materials (Form B)}

This form will help us determine if accommodations to your course content are needed. If accommodations are needed, Student Disability Services (SDS) and the Center for Distributed Learning (CDL) will work with you to assist you in making these accommodations.

* Required

Your Name: $*$

Your Email Address: *

Course/Section/Semester: *

Term *

$$
\begin{array}{cl}
C & 2013 \text { Spring } \\
\hline & 2013 \text { Summer } \\
\hline \quad & 2013 \text { Fall } \\
\hline & \text { 2014 Spring }
\end{array}
$$

What is in your course? * Please select the appropriate radio buttons below to indicate whether or not the following components are used in the online portion of course mentioned above.

$$
\text { Yes No Don't Know }
$$

Quizzes/Exams with images

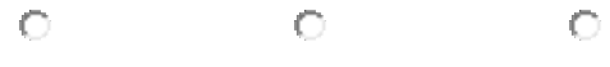

HTML/Course/Web pages

MS Word documents

$\begin{array}{lll}0 & 0 & 0 \\ 0 & 0 & 0\end{array}$




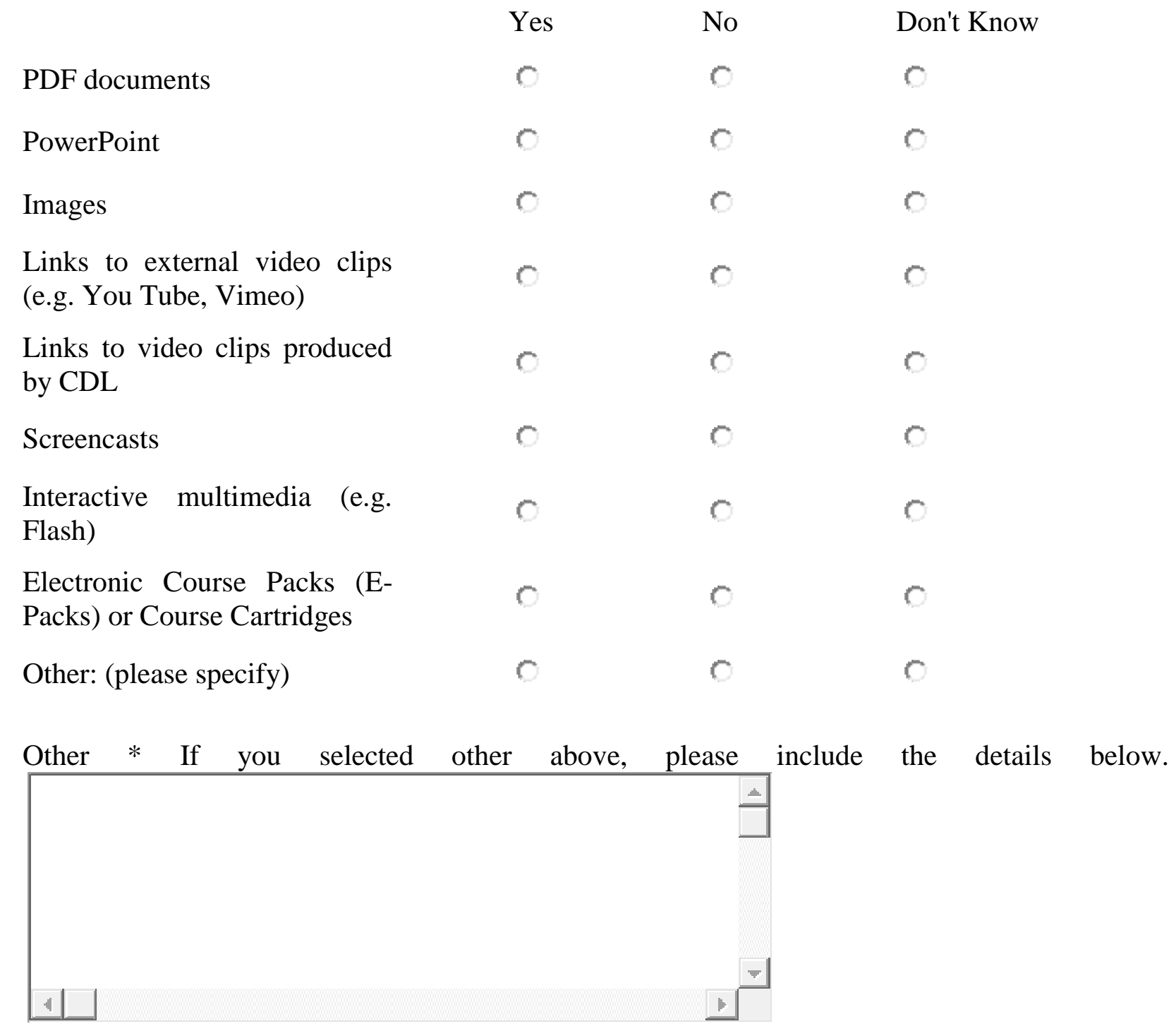

1st four weeks * Please list any specific materials from the list above that you will be using during the first 4 weeks of classes to help us prioritize them while we evaluate the rest of your course. For each item, please tell us the file name, file type, and where in your course we can find the file.

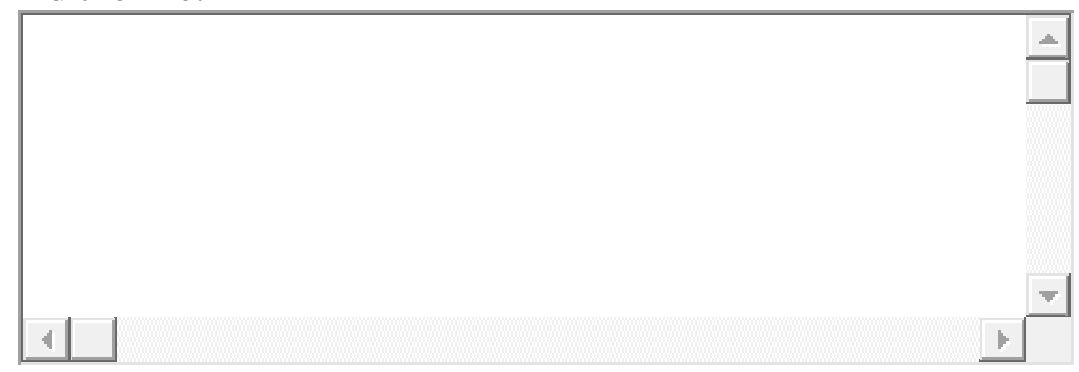

Powered by Google Docs 


\section{Checklist for Accessibility Accommodation of Online Course Materials (Form D)}

This form will help us determine if accommodations to your course content are needed. If accommodations are needed, Student Disability Services (SDS) and the Center for Distributed Learning (CDL) will work with you to assist you in making these accommodations.

* Required

Your Name: $*$

Your Email Address: *

Course/Section/Semester: $*$

Term *

$$
\begin{array}{ll} 
& 2013 \text { Spring } \\
& 2013 \text { Summer } \\
\text { C } 2013 \text { Fall } \\
\text { C } 2014 \text { Spring }
\end{array}
$$

What is in your course? * Please select the appropriate radio buttons below to indicate whether or not the following components are used in the online portion of course mentioned above.

$$
\text { Yes No Don't Know }
$$

Quizzes/Exams with audio

Narrated PowerPoint

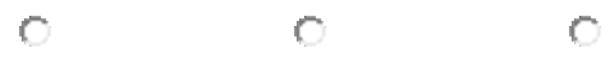

Links to external video clips

(e.g. You Tube, Vimeo)

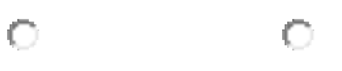

Links to video clips produced by CDL

Screencasts with audio

Interactive multimedia with audio (e.g. Flash)

Electronic Course Packs (EPacks) or Course Cartridges

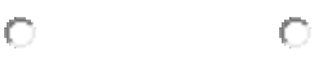

Other: (please specify)

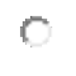

C
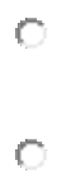

C
C

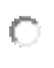

$\mathrm{C}$

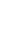

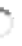

C

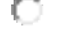

$C$

C

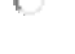

C

$C$
$C$

C

C

$C$ 


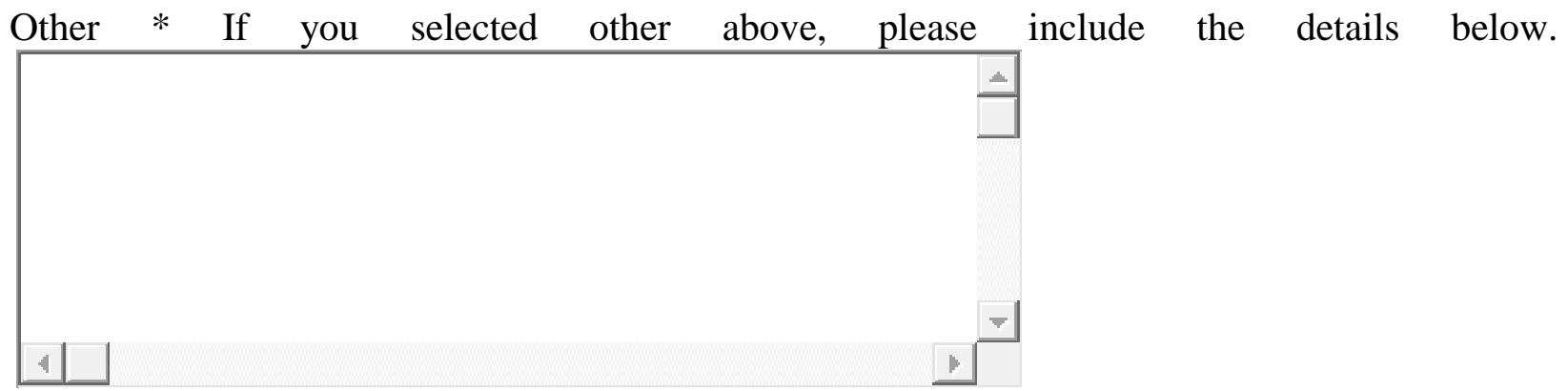

1st four weeks * Please list any specific materials from the list above that you will be using during the first 4 weeks of classes to help us prioritize them while we evaluate the rest of your course. For each item, please tell us the file name, file type, and where in your course we can find the file.

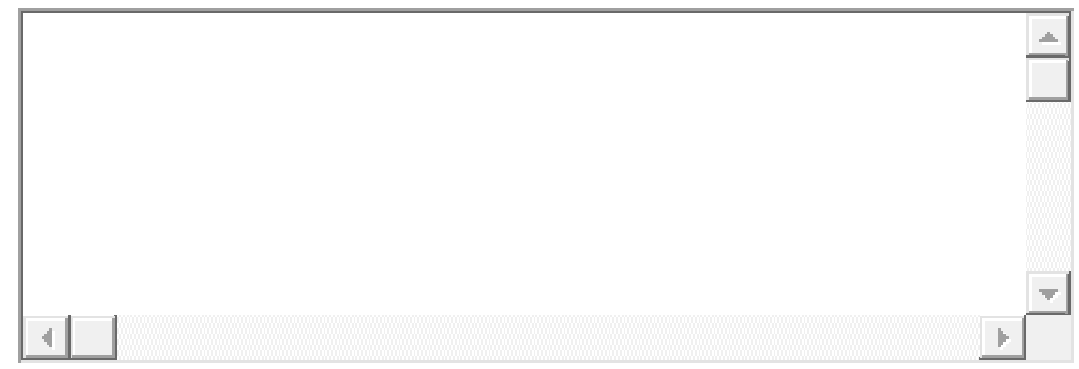

Powered by Google Docs 


\section{APPENDIX B:}

UCF Online Accessibility Accommodation Workflow

\section{UCF ONLINE ACCESSIBILITY ACCOMMODATION WORKFLOW}

\section{1}

* SDS emails faculty 4 weeks before classes begin to provide notice that a student with a disability is enrolled in the faculty's online course. Email includes the following:

a. The student's disability

b. Link to appropriate online form for faculty to complete

i. Checklist for Accessibility Accommodation of Online Course Materials (Form B)

ii. Checklist for Accessibility Accommodation of Online Course Materials (Form D)

6

CDL contacts faculty with proposed action plan and copies SDS.

CDL consults with SDS to determine accommodation priorities.
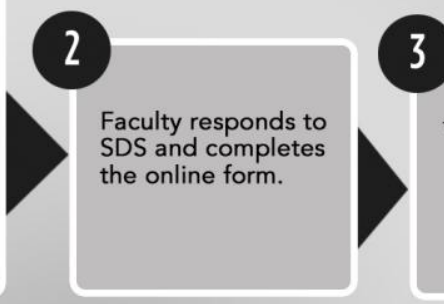
priorities.

\section{7}

$\mathrm{CDL}$ and SDS implement action plan:

a. CDL contacts appropriate internal teams to review or fix documents and/or media that need to be made accessible

b. SDS provides transcripts for media

\section{8}

$\mathrm{CDL}$ sends faculty a summary of completed course accommodations and copies SDS.

\section{4}

CDL screens online course materials for possible accommodations.
$+\mathrm{CDL}$ reviews the online form.

Faculty reviews changes and

submits follow-up requests as needed.
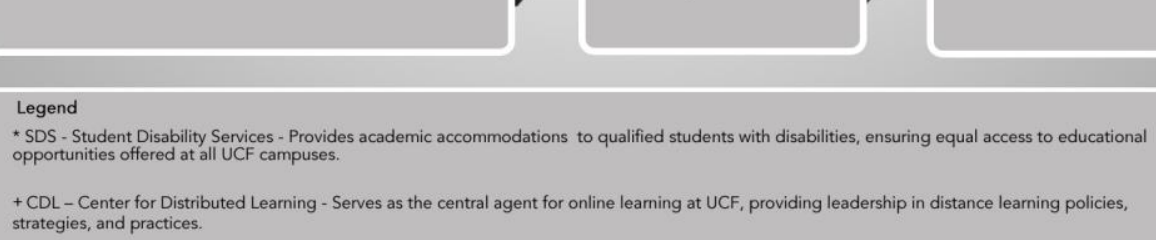